\title{
Sudden unexplained early neonatal death or collapse: a national surveillance study
}

\author{
Tracey L. Lutz ${ }^{1,2}$, Elizabeth J. Elliott ${ }^{3,4}$ and Heather E. Jeffery ${ }^{1,2}$
}

BACKGROUND: The incidence of sudden unexpected early neonatal death (SUEND) or acute life-threatening events (ALTEs) is reported as $0.05 / 1,000$ to $0.38 / 1,000$ live births. There is currently no national system in Australia for reporting and investigating such cases.

METHODS: A 3-y prospective, national surveillance study, run in collaboration with the Australian Pediatric Surveillance Unit (APSU). Data were provided by pediatricians reporting to APSU; and independently ascertained by the Coroner in two states (NSW and QLD) and the Newborn Early Transport Network in NSW. A detailed deidentified questionnaire was created.

RESULTS: In NSW and QLD, the incidence was 0.1 and $0.08 / 1,000$ live births, respectively. Forty-eight definitive cases were identified. Common causes included accidental asphyxia, cardiac disease, persistent pulmonary hypertension of the newborn, and sudden infant death syndrome. Twenty-six babies collapsed on day 1 and 19 were found on the carer's chest.

CONCLUSION: The incidence in NSW and QLD is higher than previously published. The first postnatal day is a vulnerable period for newborns, who require close observation particularly during skin-to-skin contact. Development and implementation of guidelines for safe sleeping in hospital are needed. Collaboration between obstetricians, midwives, and pediatricians is essential to ensure safety of the newborn.

$\mathbf{T}$ he sudden and unexpected death of an infant (SUDI) is defined as a death of an infant less than $1 \mathrm{y}$ of age, which is unexpected and initially unexplained. When the death remains unexplained after thorough case investigation, including a complete autopsy, examination of the death scene, and review of the clinical history, this is referred to as sudden infant death syndrome (SIDS). Both SUDI and SIDS are well defined and characterized, and sudden unexplained neonatal death accounts for about $15 \%$ of all SUDI (1). In a retrospective, population-based review of neonatal deaths in NSW (1996-2008), there were 3,732 neonatal deaths, of which $123(3.3 \%)$ were sudden and unexplained; 37 of these occurred within the first $7 \mathrm{~d}$ of life (1).

The sudden, unexpected death or collapse of apparently healthy neonates was first described in 1985 by Polberger and
Svenningsen (2) with a case series of 13 babies who died or had an acute life-threatening event (ALTE) on the maternity ward. In the United States, Burchfield and Rawlings (3) described sudden death in apparently healthy newborns in a maternity hospital in 1991. In 2011, a report from the American Academy of Pediatrics emphasized that there was insufficient evidence to recommend bed sharing in the hospital or at home (4). Following this statement, Thach highlighted neonatal deaths that occurred while bed sharing in maternity units (5). Recent data from Germany, Sweden, and England estimate an incidence of early unexpected neonatal death of between 0.05 and 0.38/1,000 live births (6-8). Two of the largest, prospective studies employed national, population-based surveillance and relied on voluntary reporting by pediatricians without any independent verification of ascertainment $(6,7)$. Although Sudden Unexplained Early Neonatal Death (SUEND) and ALTE are rare, they are associated with a high mortality and significant neurodevelopmental disability in survivors. ALTE in this study is defined as sudden collapse significant enough to require at least $1 \mathrm{~h}$ of ventilation. Previously described risk factors include primigravid women, early skin-to-skin contact, and mothers falling asleep during breastfeeding. Maternal analgesia, bed sharing, and prone sleeping are also identified risk factors (2-14). In one study (3), the majority of collapses occurred between $11 \mathrm{pm}$ and $6 \mathrm{am}$; in another there was an increased risk if mothers were health care professionals (6). SUEND and ALTE have not been studied in Australia, nor have the potential for prevention by perinatal health providers been explored.

The aim of this study was to determine the incidence of SUEND/ALTE and record underlying etiologies and risk factors so that preventative strategies could be identified and implemented in Australia. We also aimed to identify the most relevant health care providers to whom education should be targeted.

\section{RESULTS}

Of the 76 potential cases of SUEND/ALTE identified throughout Australia during the study period, 5 were duplicates, 19 did not meet the case definition, and 4 questionnaires were not returned ( $92 \%$ return rate). Of the 48 infants included in the study (27 SUEND; 21 ALTE), 38 (79\%) were notified only

\footnotetext{
'Department of Public Health, University of Sydney, Sydney, Australia; ${ }^{2}$ The Department of Newborn Care, Royal Prince Alfred Hospital, Sydney, Australia; ${ }^{3}$ The Sydney Children's Hospitals Network, Westmead, Australia; ${ }^{4}$ Discipline of Paediatrics and Child Health, Sydney Medical School, Sydney, Australia. Correspondence: Tracey L. Lutz (tracey.lutz@ sswahs.nsw.gov.au)

Received 22 January 2016; accepted 30 March 2016; advance online publication 6 July 2016. doi:10.1038/pr.2016.110
} 
through APSU and 10 identified only by the Coroner. It is estimated that there were 851,313 births $\geq 37$ wk in Australia in the 3 y 2012-2014, giving an overall incidence of SUEND and ALTE of 0.056/1,000 live births (15). Table 1 demonstrates the actual and the expected incidence by state.

\section{Maternal and Neonatal Demographic Data}

Twenty-two mothers (46\%) of cases were primigravid, compared to a national rate of $42 \%$ (15). No mother was identified as a smoker; however, status was unknown in more than $50 \%$ of cases. Delivery was vaginal in $67 \%$ of infants, by lower segment caesarean section in $25 \%$, via assisted delivery (vacuum or forceps) in $6 \%$, and in $2 \%$ the mode of delivery was not documented. The mean gestation was $38.7 \mathrm{wk}$ and mean birth weight $3,179 \mathrm{~g}$. Only two babies (4\%) were small for gestational age $(<10$ th percentile). There were 28 male infants (58\%), including one set of identical twins. Sixty-eight percent of babies experienced their ALTE while still in hospital postnatally. Three mothers (6\%) identified as Indigenous (either Aboriginal or Torres Strait Islander), compared to the national rate of $4 \%$ (15). Australian data suggest that $21 \%$ of women are prescribed opiates in the peripartum period; in this study population $40 \%$ of women were given opiates, a likely underestimate because there was no documentation in $20 \%$ of mothers (15). Only one mother identified herself as a medical professional.

\section{Short-Term Outcomes}

Twenty-seven of the 48 neonates died (56\%). Of these, 15 were found dead (SUEND) and 12 were neonates who died following an ALTE. Of the 21 survivors, 13 had a normal neurological examination in hospital and were tolerating full sucking feeds on discharge. Four cases had abnormal neurological signs documented prior to discharge and in four the neurology findings were not recorded.

\section{Timing of Collapse}

Of the 26 episodes of SUEND/ALTE on day 1 of postnatal life, 22 occurred within the first $6 \mathrm{~h}$ of life. Seventy-seven percent of all events occurred within the first $3 \mathrm{~d}$ of life (Figure 1).
In babies with delayed respiratory and circulatory physiological adaptation to extrauterine life, the median time of collapse was $63 \mathrm{~min}$ (range $15 \mathrm{~min}-4 \mathrm{~h}$ ).

\section{Circumstances Surrounding Collapse}

Nineteen of the 48 cases were found on the carer's chest; i.e., either having skin-to-skin contact with the mother while lying in bed or with the father in a bedside chair. Fifteen of these episodes occurred on day 1 of life while 18 occurred in hospital prior to discharge. Six babies were bed sharing with one or more parent at the time of death or collapse. Of the 10 babies found in their cot, 1 was nursed prone and in the other 9 cases a cause of death was established (Table 2). Sixty-eight percent of all babies collapsed or died prior to discharge from hospital.

\section{Etiology}

The established causes of ALTE are shown in Table 3. Presumed accidental asphyxia was the commonest diagnosis (6 of 11 babies died). The cardiac etiology was diverse as described in Table 3. Ten babies had confirmed persistent pulmonary hypertension of the newborn on point-of-care ultrasound. The two babies with congenital lactic acidemia were identical monochorionic diamniotic twins. Postmortems were done on

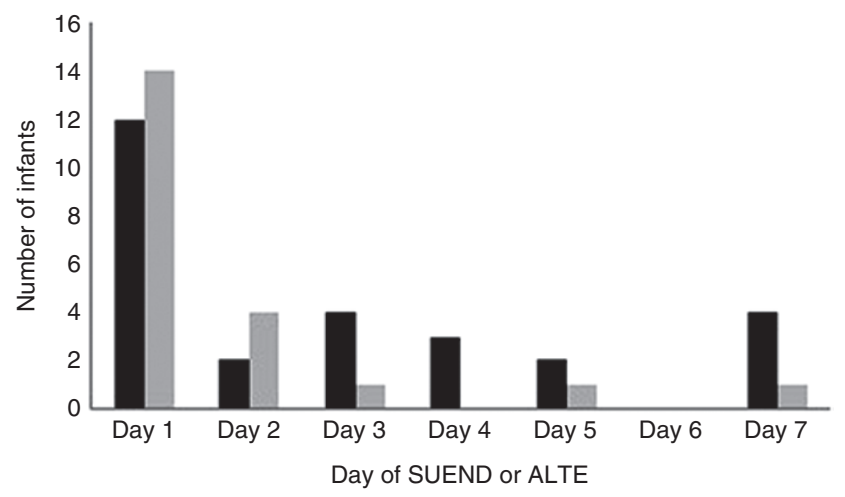

Figure 1. This figure demonstrates the number of infants who have died (sudden unexpected early neonatal death (SUEND)) or collapsed (acute life-threatening event (ALTE)) plotted against the day of life.

Table 1. The incidence of SUEND and ALTE by individual state in Australia

\begin{tabular}{|c|c|c|c|c|c|}
\hline \multirow[b]{2}{*}{ State } & \multirow{2}{*}{$\begin{array}{l}\text { Birth rate }>37 \mathrm{wk} \\
\text { per annum }\end{array}$} & \multicolumn{2}{|c|}{ Deaths } & \multirow{2}{*}{$\begin{array}{l}\text { Incidence of SUEND and ALTE } \\
\text { (per 1,000 live births per annum) }\end{array}$} & \multirow{2}{*}{$\begin{array}{l}\text { Expected No. of cases if } \\
\text { true incidence } 0.1 / 1,000^{\text {a }}\end{array}$} \\
\hline & & SUEND & ALTE & & \\
\hline North South Wales & 91,370 & 16 & 13 & $0.1^{\mathrm{a}}$ & 29 \\
\hline Victoria & 57,439 & 1 & 3 & 0.01 & 21 \\
\hline Western Australia & 30,662 & 0 & 1 & 0.01 & 9 \\
\hline Northern Territory & 3,620 & 0 & 0 & 0 & 1 \\
\hline Tasmania & 5,299 & 0 & 0 & 0 & 2 \\
\hline Australian Capital Territory & 5,442 & 0 & 0 & 0 & 2 \\
\hline Total & 283,771 & 27 & 21 & 0.05 & 0.1 \\
\hline
\end{tabular}

ALTE, acute life-threatening event; SUEND, sudden unexplained early neonatal death.

a In NSW three sources of case ascertainment were used (coroner, NETS, and voluntary reporting) to optimize the estimate of incidence of SUEND and ALTE. 
23 of the 27 babies who died, and another 2 had limited skin, muscle, and liver biopsies. In two cases, autopsies were not performed because the cause of death was presumed to be known (hypoxic-ischemic encephalopathy (HIE) which is an acute brain injury due to asphyxia and metabolic disease, respectively) although the underlying causes were never defined.

\section{DISCUSSION}

In NSW and QLD, there was optimal ascertainment of SUEND associated with use of additional and independent sources of cases, including coroner's reports in NSW and QLD and ascertainment of ALTE's by independent reporting via Newborn Early Transport Network (NETS) in NSW. Based on the 48 cases identified in our study, we estimated the incidence of SUEND or collapse for Australia was 0.05 per 1,000 live births per annum, which is comparable with international data (0.026-0.05 per 1,000 live births). In NSW, with optimal reporting, the incidence was $0.1 / 1,000$ live births. The twofold difference in incidence in Australia compared to NSW suggests the reticence of clinicians to report and/or investigate cases. This is also reflected in the fact that autopsies were not performed in two babies and that limited biopsies were performed on another two babies. Failure to establish a cause for death leaves parents uninformed and prevents access to relevant information that may impact on future pregnancies.

Prior to this study, there are only two other national prospective surveillance studies reporting on SUEND $(6,7)$. This is the first prospective, population-based study where independent reporting of Coroner's (NSW and QLD) and NETS data (NSW) was included to ensure ascertainment of all cases in two states. In other Australian states, there was voluntary reporting by physicians only; similar to the studies reported in

Table 2. Position when found with SUEND or ALTE

\begin{tabular}{|c|c|c|c|c|}
\hline Position found & No. of cases & Event occurred in hospital & No. of deaths & Cause of ALTE or death \\
\hline Carer's chest & 19 & 19 & 6 & $\begin{array}{l}\text { Four cardiac disease, six PPHN, seven accidental asphyxia, } \\
\text { one SIDS, and one airway abnormality }\end{array}$ \\
\hline Bed sharing with parents & 6 & 1 & 5 & Four accidental asphyxia and two SIDS \\
\hline Not known & $9^{c}$ & & & \\
\hline
\end{tabular}

ALTE, acute life-threatening event; PPHN, persistent pulmonary hypertension of the newborn; SIDS, sudden infant death syndrome; SUEND, sudden unexplained early neonatal death.

ane neonate nursed prone. ${ }^{b}$ Unknown — awaiting postmortem results. ${ }^{c}$ Not known as not reported in questionnaire.

Table 3. Etiology of SUEND or ALTE

\begin{tabular}{|c|c|c|c|c|}
\hline Diagnosis & Specific diagnosis & No. of cases & No. of deaths & $\begin{array}{l}\text { Abnormal } \\
\text { neurology }\end{array}$ \\
\hline \multicolumn{5}{|l|}{ Failure to establish safe skin to skin } \\
\hline \multicolumn{5}{|c|}{ Fatal or potentially fatal conditions (lack of recognition) } \\
\hline Cardiac disease & $\begin{array}{l}\text { HLHS, TGA, interrupted aortic arch, myocardial infarction, } \\
\text { critical pulmonary stenosis }\end{array}$ & 9 & 3 & $0 ; \mathrm{DK} 3$ \\
\hline Sepsis & Pneumonia, meningitis & 5 & 5 & NA \\
\hline Metabolic & Congenital lactic acidemia, urea cycle defect & 3 & 3 & NA \\
\hline Hypovolemia & Subgaleal hemorrhage, placenta praevia with placental loss & 2 & 2 & NA \\
\hline Airway abnormality & $\begin{array}{l}\text { Prolapsed epiglottis with laryngomalacia (requiring } \\
\text { supraglottoplasty) }\end{array}$ & 1 & 0 & 1 \\
\hline \multicolumn{5}{|l|}{ Unexplained cause of death/collapse } \\
\hline SIDS & SIDS & 4 & 4 & NA \\
\hline Unknown & & 3 & 1 & \\
\hline
\end{tabular}

Total number is 49 as one baby with PPHN had confirmed sepsis.

ALTE, acute life-threatening event; DK, don't know; HLHS, hypoplastic left heart syndrome; NA, not applicable; PPHN, persistent pulmonary hypertension of the newborn; SIDS, sudden infant death syndrome; SUEND, sudden unexpected early neonatal death; TGA, transposition of the great arteries. 


\section{Articles | Lutzetal.}

the United Kingdom and Germany $(6,7)$. This Australian study confirms international findings that early skin-to-skin positioning, primigravid mothers, and use of peripartum opiates are risk factors for SUEND and ALTE. The UK and German studies report events in the immediate postnatal period (12-24h); however, given the authors' awareness of other cases with similar etiology that fell outside of the 12- to 24-h definition, the criteria for this study was deliberately expanded to include infants up to $7 \mathrm{~d}$ of life.

Unlike SUDI in the older infant, the etiology of life-threatening events in the neonatal group is identified in the majority. Presumed accidental asphyxia, cardiac disease, sepsis, and persistent pulmonary hypertension are the commonest identifiable and preventable causes in this study. The neonates with accidental asphyxia were all found in positions that compromise the airway; i.e., on the carer's chest, while bed sharing, or flexed in the father's arms. Our study indicates that the first $6 \mathrm{~h}$ postdelivery is a particularly vulnerable time for rapid death from accidental asphyxia.

The early postnatal period is an important time for early bonding between mother and baby, and skin-to-skin contact is important to facilitate temperature control, breastfeeding, and maternal attachment. However, given that this is a vulnerable period for the newborn baby, health care providers need to be aware of the risk of an ALTE and provide close supervision especially during skin-to-skin contact and bed sharing and breast feeding.

It is evident that babies with physiological maladaptation from intrauterine to extrauterine life also benefit from early recognition and treatment. Some authorities have even suggested the presence of two professionals during delivery of babies at risk, one for the clinical care of the mother and the other to provide care and monitor the baby. Due to staff shortages, this policy is rarely if ever implemented (16). As part of a surveillance protocol Davanzo et al. recently published a checklist (heart rate, saturations, positioning of the airway, and color of the baby) for newborn infant monitoring in the first $2 \mathrm{~h}$ of life, particularly during skin-to-skin contact (17). Education of health care professionals is essential in prevention of SUEND and ALTE, particularly obstetricians and midwives who manage the healthy mother and baby pair. As Tracy et al. clarified pediatricians in the United States do not see the majority of healthy neonates during their hospital stay and a similar situation pertains to Australia (18).

Obstetric staff receive extensive training in the care and delivery of a pregnant women; however, this training is not extended to care of the newborn in the relevant curricula in the United States, Canada, the United Kingdom, and Australia. Tracy et al. recognized the importance of teaching newborn safety routinely in obstetric curricula and recommended that the American College/Congress of Obstetricians and Gynaecologists and the American Academy of Pediatrics should partner to disseminate information and clinical guidelines (18).

Maternal fatigue and the influences of prescribed analgesia in the peripartum period are risk factors for adverse neonatal events as a consequence of mothers falling asleep while breastfeeding or experiencing reduced awareness. NSW Health has a policy directive in place "Maternity-Safer Sleeping practices for babies in NSW public health organisations," which was in response to a number of unexpected neonatal deaths or life-threatening events. There is currently no process in place in Australia to enable clinicians to register these events on a population-wide basis, and there are no national guidelines for safe sleeping in the hospital setting. In most instances in our study, the condition of the baby was not identified by one of the parents, but rather by the midwife. This suggests that parental education may be of benefit in recognizing and preventing these rare but catastrophic events. Our prospective study demonstrated that there were more than five early, unexpected neonatal deaths in NSW per year compared to the three per year identified in the retrospective review conducted between 1996 and 2008 (ref. (1)). Possible explanation for this include previous underreporting of SUDI, as apparently occurred in some states in the current study, or recent behavioral changes in maternity practices with the routine use of early skin-toskin contact following evidence to support its benefits (19).

In the majority of tertiary neonatal units and larger special care nurseries in Australia, it is common practice to perform postductal oxygen saturation in all neonates at $48 \mathrm{~h}$ of age or prior to discharge from hospital in order to detect congenital heart disease. Only a few centers also check oxygen saturation in the immediate postnatal period (within $6 \mathrm{~h}$ ). A large prospective, multicenter study in Norway indicated that early saturation screening detects congenital heart disease, pulmonary disease, and maladaptation associated with transitional circulation from fetal to neonatal life (20). Fetal anomaly scans during pregnancy, early oxygen saturation screening, and a comprehensive clinical examination could potentially prevent the majority of cases of collapse from cardiac disease and from persistent pulmonary hypertension of the newborn. The authors recognize that the level of prenatal and postnatal care may differ in various geographical areas throughout Australia and impact on timely diagnosis of cardiac disease. Other useful preventative strategies include the early identification of risk factors for sepsis (maternal fever, prolonged rupture of membranes, and maternal group B streptococcal colonization) and monitoring of babies for subgaleal hemorrhage through the implementation of the Royal Australasian and New Zealand College of Obstetricians and Gynaecologists policy of observation of babies delivered by ventouse (21).

Currently in Australia, investigation for the cause of collapse or death is conducted on an ad hoc basis with no available clinical guidelines. Guidelines are particularly important given the rarity of these events. Under legislation in Australian States and Territories, every baby that dies unexpectedly should be referred to a coroner, and when the cause of death cannot be determined a postmortem should be performed. It is essential that pathologists who perform these postmortems have the necessary expertise in pediatrics. The literature suggests that a pediatric pathologist or combined forensic/pediatric pathologist is optimal for determining cause of death (22). Comprehensive investigation of these cases allows families to understand the cause 
of death, which may impact on subsequent pregnancies. In this study four babies did not have a full postmortem.

The strengths of this study include the prospective collection of data and excellent case ascertainment in two states. In NSW, where reporting was sourced from a combination of the APSU, the Coroner, and a retrieval service (NETS NSW), optimal ascertainment was ensured. The main limitations of the study are the small number of patients and under-ascertainment in other states where voluntary reporting by pediatricians through the APSU was relied upon. Any direct comparison with previous literature beyond the first day of life is limited due to the extended inclusion time in this study. Also, although the neurological outcome on discharge was documented, we understand the need for ongoing pediatric follow-up beyond infancy as neurodevelopmental delay is often not appreciated until later. It would be very useful to access and document the long-term outcomes of the survivors.

\section{METHODS}

This is a descriptive, prospective, national surveillance study, conducted between 1 January 2012 and 31 December 2014 in collaboration with the Australian Paediatric Surveillance Unit (APSU), a national resource established in 1993 to facilitate voluntary reporting of rare conditions. Pediatric specialists throughout Australia report incident cases to the APSU via monthly emails. In addition, we accessed all cases recorded by coroners in NSW and QLD, two of Australia's most populous states (52\% of Australia's births in 2012) for the 3-y period (15). In NSW, all ventilated newborns are managed in seven perinatal centers and two pediatric intensive care units. The Newborn and Paediatric Emergency Transport Service (NETS) in NSW was utilized as an additional source of cases of sudden unexpected neonatal collapse, because all ventilated newborns are referred by practitioners to tertiary centers via this service.

The case definition for this study was "the sudden unexpected neonatal death or postnatal collapse of an apparently healthy infant ( $\geq 37$ wk gestation) who was deemed well enough for routine postnatal care and either died or required intensive care (at least $1 \mathrm{~h}$ of ventilation) within the first $7 \mathrm{~d}$ of life." Babies with known severe congenital anomalies at birth, babies older than $7 \mathrm{~d}$, and babies who required minimal resuscitation and did not require intensive care were excluded. Approximately 1,400 Australian pediatricians are requested to report to the APSU on listed rare conditions in response to a monthly email. Nonsubmission is followed up by the APSU. The treating physician then completes a detailed, de-identified threepage questionnaire providing demographic details, details about the birth and labor, antenatal and postnatal history, circumstances and management around the collapse, and the short-term outcome of the baby. Results from clinical investigations and postmortems were also recorded. The information was all de-identified and therefore no parental consent was required.

Most data were summarized using descriptive statistics and analyzed using SPSS version 22.0 (released 2013; IBM Corp, Armonk, NY). The incidence was calculated based on the number of notified cases per state divided by the birth rate in each state calculated over a 3-y period (15). Ethical approval for the study was obtained from the Sydney South West Area Health Service Human Ethics and Research Committee (X11-0273).

\section{Conclusion}

The cause of SUEND or ALTE is often identifiable and preventable. Although rare, the mortality rate is high and survivors have significant neurodevelopmental disability. There is a need for the development and implementation of national guidelines on safe sleeping within the hospital setting and in the community. Investigation of cases of unexpected death and collapse must be comprehensive to ensure the cause is identified and a national guideline would assist. Importantly, obstetricians, midwives, and neonatologists/pediatricians need to collaborate to ensure newborn safety.

\section{ACKNOWLEDGMENTS}

We acknowledge all pediatricians who contribute cases to the Australian Paediatric Surveillance Unit. We would like to thank the families involved as well as the Queensland Family and Child Commission and the NSW Ombudsman.

The abstract was presented at the Perinatal Society of Australia and New Zealand April 2015, Melbourne, Australia.

\section{STATEMENT OF FINANCIAL SUPPORT}

A special thank you to SIDS and Kids (Sydney, Australia) for funding the study for 3 years. The Australian Paediatric Surveillance Unit activities are supported by the Australian Government Department of Health and Ageing. E.E. is supported by an NHMRC Practitioner Fellowship (\#APP1021480).

Disclosure: The authors report no conflict of interest.

\section{REFERENCES}

1. NSW Child Death Review Team Report. A preliminary investigation of neonatal SUDI in NSW 1996-2008: opportunities for prevention, NSW Commission for Children and Young People, 2010. (http://kids.nsw.gov. au/uploads/documents/FinalSUDIneonates.pdf.)

2. Polberger S, Svenningsen NW. Early neonatal sudden infant death and near death of fullterm infants in maternity wards. Acta Paediatr Scand 1985;74:861-6.

3. Burchfield DJ, Rawlings DJ. Sudden deaths and apparent life-threatening events in hospitalized neonates presumed to be healthy. Am J Dis Child 1991;145:1319-22.

4. Moon R, Darnall R, Goodstein M, Hauck FR. SIDS and other sleep-related infant deaths: expansion of recommendations for a safe infant sleeping environment. Pediatrics 2011; 128:1030-39.

5. Thach BT. Deaths and near deaths of healthy newborn infants while bed sharing on maternity wards. J Perinatol 2014;34:275-9.

6. Becher J, Bhushan S, Lyon A. Unexpected collapse in apparently healthy newborns - a prospective national study of a missing cohort of neonatal deaths and near death events. Arch Dis Child Fetal Neonatal Ed 2012; 97:F30-34.

7. Poets A, Steinfeldt R, Poets CF. Sudden deaths and severe apparent lifethreatening events in term infants within 24 hours of birth. Pediatrics 2011;127:e869-73.

8. Herlenius E, Kuhn P. Sudden unexpected postnatal collapse of newborn infants: a review of cases, definitions, risks, and preventive measures. Transl Stroke Res 2013;4:236-47.

9. Rodríguez-Alarcón J, Melchor JC, Linares A, et al. Early neonatal sudden death or near death syndrome. An epidemiological study of 29 cases. Acta Paediatr 1994;83:704-8.

10. Grylack LJ, Williams AD. Apparent life-threatening events in presumed healthy neonates during the first three days of life. Pediatrics 1996;97: 349-51.

11. Hays S, Feit P, Barré P, et al. [Respiratory arrest in the delivery room while lying in the prone position on the mothers' chest in 11 full term healthy neonates]. Arch Pediatr 2006;13:1067-8.

12. Nakamura T, Sano Y. Two cases of infants who needed cardiopulmonary resuscitation during early skin-to-skin contact with mother. J Obstet Gynaecol Res 2008;34(4 Pt 2):603-4.

13. Dageville C, Pignol J, De Smet S. Very early neonatal apparent life-threatening events and sudden unexpected deaths: incidence and risk factors. Acta Paediatr 2008;97:866-9.

14. Leow J, Ward Platt MP. Sudden unexpected and unexplained early neonatal deaths in the North of England. Arch Dis Child Fetal Neonatal Ed 2011; 96:6: F440-42.

15. Australian Institute of Health and Welfare. Australia's mothers and babies 2012. Perinatal statistics series no. 30, 2014. (http://www.aihw.gov.au/ WorkArea/DownloadAsset.aspx?id=60129550054.)

16. Association of Women's Health, Obstetric and Neonatal Nurses. Guidelines for professional registered nurse staffing for perinatal units, 2014. (https://www.awhonn.org.) 


\section{Articles | Lutzetal.}

17. Davanzo R, De Cunto A, Paviotti G, et al. Making the first days of life safer: preventing sudden unexpected postnatal collapse while promoting breastfeeding. J Hum Lact 2015;31:47-52.

18. Tracy EE, Haas S, Lauria MR. Newborn care and safety: the black box of obstetric practices and residency training. Obstet Gynecol 2012;120: 643-6.

19. Moore E, Anderson G, Bergman N, Dowswell T. Early skin to skin contact for mothers and their healthy newborn infants. The Cochrane Library 2012. http://onlinelibrary.wiley.com/doi/10.1002/14651858.CD003519. pub3/full
20. Meberg A, Brügmann-Pieper S, Due R Jr, et al. First day of life pulse oximetry screening to detect congenital heart defects. J Pediatr 2008;152:761-5.

21. The Royal Australian and New Zealand College of Obstetricians and Gynaecologist (RANZCOG). Prevention, detection and management of a subgaleal haemorrhage in the newborn, 2015. (https://www.ranzcog.edu.au/ college-statements-guidelines.html).

22. The Royal College of Pathologists and the Royal College of Paediatrics and Child Health. Sudden unexpected death in infancy. A multi-agency protocol for care and investigation, 2004. (http://www.rcpch.ac.uk/sites/default/ files/page/SUDI_report_for_web.pdf.) 